\title{
Vozes inauditas em um currículo colonizado: "Eu quero um país que não está no retrato"1
}

Edilaine Ricardo Machado* Celina Nunes de Alcântara**

\section{Resumo:}

Neste artigo interpela-se a relação de desigualdade entre a abordagem da cultura eurodescendente e as culturas negra e indígena nos currículos escolares como decorrente de modos hegemônicos e colonizados de abordagem curricular. Trabalha-se com a noção metafórica de vozes inauditas para pensar as diferentes referências culturais brasileiras silenciadas e apagadas do processo educacional escolar brasileiro. Discute-se a relação entre os conceitos de racismo epistêmico, subordinação epistêmica, colonialismo e colonialidade. Indica-se alguns dos possíveis efeitos da ação de tais conceitos sobre as formulações curriculares vigentes, além de sua interferência na instauração de relações étnico-raciais díspares, que são verificáveis entre os sujeitos de diferentes pertencimentos raciais que habitam o cotidiano escolar. Aponta-se a proposição dos Estudos da Performance como possibilidade de subverter as práticas curriculares correntes. Projeta-se que, por intermédio de tal subversão, seja possível agregar outras experiências epistemológicas aos programas escolares, na expectativa de construção de um currículo decolonial.

\section{Palavras-chave:}

Currículo. Performance. Decolonialidade

\begin{abstract}
:
In this article the unequal relationship between the approach to Eurodescendant history and culture and black and indigenous history and culture in school curricula as a result of hegemonic and colonized ways of curricula approaching is interpellated. It works with the metaphorical notion of unheard voices to think about the different Brazilian cultural references silenced and erased from the Brazilian school educational process. The relationship between the concepts of epistemic racism, epistemic subordination, colonialism and coloniality is discussed. Some of the possible effects of the action

1. O subtítulo do artigo, assim como os títulos de cada uma das seções, são trechos extraídos do samba-enredo "História para ninar gente grande" (2019), da escola de samba Estação Primeira da Mangueira.

* Edilaine Ricardo Machado (Dedy Ricardo) é atriz e professora do Departamento de Expressão e Movimento do Colégio de Aplicação da UFRGS, na área de Teatro. É integrante do Coletivo Atinuké e do grupo Usina do Trabalho do Ator, em Porto Alegre. E-mail: dedyricardo.dr@gmail.com. ORCID iD: https://orcid.org/0000-0002-5650-5222.

** Celina Nunes de Alcântara (Celina Alcântara) é atriz, professora e pesquisadora. Atua na graduação em Teatro do Departamento de Arte Dramática e no Programa de Pós-Graduação em Artes Cênicas, do Instituto de Artes, da UFRGS. É também integrante e fundadora do grupo Usina do Trabalho do Ator. E-mail: celinanalcantara@gmail.com. ORCID iD: https://orcid. org/0000-0001-6546-2765.
\end{abstract}


of such concepts on the curricular formulations currently in force, in addition to their interference in the establishment of disparate ethnic-racial relations, which are verifiable among subjects of different racial backgrounds that inhabit the school everyday life, are indicated. The proposal of Performance Studies is pointed out as a possibility to subvert current curricular practices. It is projected that, by such subversion, it will be possible to add other epistemological experiences to school programs, in the expectation of building a decolonial curriculum.

\title{
Keywords:
}

Curriculum. Performance. Decoloniality.

\section{Introdução: "abre alas pros teus heróis de barracões"}

\author{
"Brasil, meu dengo, a Mangueira chegou \\ Com versos que o livro apagou \\ Desde 1500 tem mais invasão do que descobrimento \\ Tem sangue retinto pisado atrás do herói emoldurado \\ Mulheres, tamoios, mulatos \\ Eu quero um país que não está no retrato."
}

"História para ninar gente grande", samba-enredo da Estação Primeira da Mangueira.

O texto transcrito acima é um trecho do samba-enredo da Mangueira, escola campeã do grupo especial do Carnaval 2019, no Rio de Janeiro. Para além de trazer uma narrativa que revela o caráter de luta e resistência intrínseco a essa manifestação negra e brasileira, tomamos essa estrofe porque acreditamos que ela aponta uma grande lacuna no currículo das instituições escolares, desde o ensino básico até os cursos de graduação. Referimo-nos às histórias que ainda estão longe de serem abordadas nos currículos, em todos os campos de conhecimento, que dizem respeito a um importante legado, qual seja, as heranças afro-brasileiras e ameríndias na constituição da nação e do povo brasileiro.

Trata-se de fatos, heróis, heroínas, autores, autoras, cientistas, inventores, inventoras, escritores, escritoras, artistas de todos os campos, líderes religiosos, mestras e mestres de saberes populares, professoras, professores, historiadoras e historiadores que também são formadoras/res desta nação, porém, permanecem à margem dos currículos escolares. Ou, dito de outra forma, falamos das vozes que permanecem inauditas, a despeito da nossa formação nacional, cuja existência foi sedimentada no trabalho, nos saberes, nos cultivos, nos sofrimentos, nas lutas, enfim, nas existências afro-brasileiras e indígenas. Essa situação ainda é uma realidade em nossas escolas, mesmo depois de dezessete anos da Lei 10639/03 (BRASIL, 2003), que instituiu a obrigatoriedade do ensino de história e cultura africana e afro-brasileira em todos os níveis da educação, assim como da Lei 11645/08 (BRASIL, 2008), que estende essa compulsoriedade à cultura e história indígena. Mas, afinal, o que são dezessete anos de uma proposição de reparação histórica, diante dos séculos de dominação cultural que pesam sobre nossos currículos?

A partir deste preâmbulo, falaremos um pouco mais tanto das vozes ausentes quanto da ideia de currículo, na intenção de propor outros modos de abordagem curricular que possam dar conta da multiplicidade, da abrangência, da complexidade, das variedades étnicas, de saberes e experiências - para dizer o mínimo - que constituem nossa concepção nacional. 


\section{"A história que a história não conta"}

Para empreendermos a busca por um país melhor, mais justo, mais desenvolvido de maneira econômica, educacional e cultural, não deveríamos começar por compreender e valorizar a própria gênese de nossas potencialidades? Ou seja, não seria coerente atentarmos, justamente, para aquilo que nos tornou uma experiência possível de nação do ponto de vista dos diferentes e complexos legados herdados a partir de três principais referências étnico-raciais distintas: indígenas, afro-brasileiros e brancos europeus?

Imaginamos que um primeiro passo importante converge no sentido de mirarmos essa constituição e reafirmá-la, não somente a partir de uma voz, representativa de um grupo, que é o branco europeu, mas recompô-la mediante as múltiplas vozes constituintes, que têm sido sistematicamente silenciadas e apagadas em nome de uma versão unívoca. Para isso, como bem apregoam os versos da Estação Primeira da Mangueira, faz-se necessário ouvir "a história que a história não conta, do avesso do mesmo lugar [...]" (HISTÓRIA..., 2019).

Para pensarmos e construirmos uma proposição curricular que dialogue com a ideia de uma escola comprometida com princípios de equidade, e que se pretenda democrática do ponto de vista das relações étnico raciais, é fundamental trazer vozes que proponham outras narrativas para o nosso passado, presente e futuro. É o caso de Antônio Bispo dos Santos (Nego Bispo), líder quilombola de uma comunidade rural do Piauí, mestre de ofícios e do componente curricular Encontro de Saberes (na Universidade de Brasília - UnB). Bispo (SANTOS, 2015), em seu livro Colonização, Quilombos: modos e significações, propõe que o processo de constituição do povo brasileiro foi calcado nas múltiplas opressões, silenciamentos e violências a que foram submetidos os povos negros africanos trazidos para cá, bem como os povos originários que aqui viviam.

Para Santos, a gênese dessa opressão está assentada em dois modos profundamente diversos de operação sobre o mundo, a saber: "a cosmovisão cristã monoteísta e a cosmovisão pagã politeísta” (SANTOS, 2015, p. 37). Bispo dimensiona essa diferença da seguinte forma:

O povo euro cristão monoteísta, por ter um Deus onipotente, onisciente e onipresente, portanto único, inatingível, desterritorializado, acima de tudo e de todos, tende a se organizar de maneira exclusivista, vertical e/ou linear. Isso pelo fato de ao tentarem ver seu Deus, olharem apenas em uma única direção. Por esse Deus ser masculino também tendem a desenvolver sociedades mais homogêneas e patriarcais. Como acreditam em Deus que não pode ser visto materialmente, se apegam muito em monismos, objetivos e abstratos. Quanto aos povos pagãos politeístas que cultuam várias deusas e deuses pluripotentes, pluricientes e pluripresentes, materializados através dos elementos da natureza que formam o universo, é dizer, por terem deusas e deuses territorializados, tendem a se organizar de forma circular e/ou horizontal, porque conseguem olhar para suas deusas e deuses em todas as direções. Por verem as suas deusas e deuses através dos elementos da natureza como, por exemplo, a água, a terra, o fogo e o ar e outros elementos que formam o universo, apegam-se a plurismos subjetivos e concretos. (SANTOS, 2015, p. 38-39).

Esse modo de operar desde uma dimensão religiosa que, por sua vez, circunscreve uma visão de mundo e um modo de agir sobre ele, desde o ponto de vista euro cristão, foi a base para o processo de colonização bem como da relação com a escravização no Brasil. Para esse líder quilombola, tratou-se de

[...] destituir os povos afro-pindorâmicos de suas principais bases de valores socioculturais, atacando suas identidades individuais e coletivas, a começar pela tentativa de substituir o paganismo politeísta pelo cristianismo euro monoteísta. No plano individual, as pessoas afro-pindorâmicas foram e continuam sendo taxadas como inferiores, religiosamente tidas como sem almas, intelectualmente tidas como menos capazes, esteticamente tidas como feias, sexualmente tidas como objeto de prazer, socialmente tidas como sem costumes e culturalmente tidas como selvagens. (SANTOS, 2015, p. 38). 
Nessa mesma perspectiva de pensamento, acerca de um paradigma religioso imposto aos colonizados e que forjou todo um conjunto de valores socioculturais, o historiador Thiago André (HISTÓRIA..., 2019) problematiza a dissonância entre as noções de corpo de cada uma das culturas envolvidas no processo de escravização negra, ao observar que,

[...] aqui no Brasil [...], o corpo negro vai ser alvo da domesticação colonial, tanto na dimensão física pelo trabalho e castigos corporais, como na dimensão simbólica, pela religiosidade e visão de mundo que deriva dela, porque na lógica da tradição católica o corpo é profano, é por meio dele que pecamos. É necessário dominar a carne, para que haja crescimento espiritual [...]. Já na visão iorubá e nas culturas de transe, a coisa é totalmente oposta: o corpo é a ponte para o sagrado, pois é por meio dele que acontece a ligação com o mundo espiritual. Enquanto uma cultura diz que o corpo te afasta de deus, a outra afirma que só pelo corpo é possível vislumbrar o divino.

Eis aí duas possibilidades de abordagem analítica, mas também de perspectivas de apresentação dos fatos que rompem com a própria lógica de construção histórica, na qual a narrativa de evangelização colonizadora foi colocada como redentora dos povos negros e indígenas, com permissão autoconcedida para o apagamento da cosmovisão desses povos e imposição de suas próprias crenças. Pensar, como aduzem Bispo e André, a experiência religiosa como um processo fundamental para a compreensão e atuação no mundo evidencia, desde uma cosmovisão diversa da eurobranca, os rumos que tomamos como nação por intermédio de escolhas e compreensões que acabaram por nos forjar como descendentes de um legado unívoco.

Para corroborar com essa abordagem, trazemos também a escrita de Marina Fazzio Simão e Juliano Camargo Sampaio (2018, p. 670), que afirmam que "[...] nosso corpo e a corporeidade que o contém e a partir da qual se forma, é também resultado da colonização que sofremos e das relações que se estabeleceram desde então". Os autores apontam ainda que "a colonização recai sobre nossas noções de corpo, nossos modos de agir, nossos modos de ser e estar no mundo" (2018, p. 668). Por isso, não se trata de fazer desaparecer a experiência do colonizador, mas fazer aparecer as importantes contribuições daqueles que foram alvo da colonização, porém não se mantiveram, de modo algum, inertes ou passivos nessa experiência, a despeito do que nos diga a narrativa oficial.

Obviamente, a melhor interpretação não se resume a efetivarmos o processo inverso, isto é, o apagamento da experiência branco-europeia, inclusive e sobretudo religiosa na nossa experiência cultural - mesmo que isso fosse possível e, de fato, não o é. Trata-se, sim, de perceber a unicidade de narrativa a que fomos restringidos como experiência de nação e de povo e o quanto tal unicidade nos tem impedido de fazer jus a todas as potências e vivências que são parte do nosso legado como sociedade. Ao considerar as vozes formadoras desse país, ainda inauditas nesta experiência de colonização a que fomos/somos submetidos há mais de cinco séculos, falaremos um pouco sobre a noção de currículo, para então propor ideias em torno de um currículo decolonial, com vistas a fazer soar as diferentes vozes/experiências étnico-culturais formadoras de quem fomos, somos e ainda poderemos vir a ser como povo.

\section{Para "tirar a poeira dos porões"}

Antes de mais nada, faz-se necessário admitir e explicitar que o currículo, da forma como é usualmente concebido, aborda o conhecimento do ponto de vista hegemônico, ou seja, branco, masculino e segundo a lógica do agente colonizador. Essa constatação, advinda não apenas de nossos estudos, mas também de nossas próprias experiências como estudantes e como professoras negras, remete-nos à advertência da escritora nigeriana Chimamanda Ngozi Adichie (2019), sobre os perigos de uma história única, que acaba por nos restringir às diferentes versões de uma mesma história. Nessa perspectiva, os povos indígenas e africanos, que foram "salvos" do paganismo, da incivilidade e da promiscuidade pelos europeus, são apresentados às (aos) estudantes como ignorantes e selvagens. Consequentemente, tais povos não têm nada a 
ensinar e precisaram - e ainda precisam - aprender muito para equiparar-se ao modelo humano almejado, isto é, o mais próximo possível do branco europeu. Desse modo, o currículo desconsidera os saberes de matriz africana - bem como dos povos originários - e os relega a um papel de coadjuvantes, de cidadãos de segunda ordem na história do Brasil.

A situação acima descrita pode ser vista como um exemplo daquilo que Nelson Maldonado-Torres (2008) define como "subordinação epistêmica", que se relaciona com a sua proposição de "racismo epistêmico". Para o autor, "[t]al como acontece com todas as formas de racismo, o epistêmico está relacionado com a política e com a sociabilidade. O racismo epistêmico descura a capacidade de certos grupos de pessoas" (2008, p. 79). Por conseguinte, o racismo deslegitima e invisibiliza os saberes oriundos daquelas(es) a quem impõe a subordinação. É possível traçar uma relação entre o conceito de colonialidade, cunhado por Aníbal Quijano, e a noção de racismo epistêmico. Quijano (1997 apud Assis, 2014) concebe a colonialidade como algo que ultrapassa as características do colonialismo histórico e que persiste para além dos processos de descolonização. O conceito de colonialidade difere da ideia de colonialismo, embora ambas as proposições estejam intimamente relacionadas.

Entendemos que o colonialismo pode ser visto como o discurso que ampara o projeto colonial, qual seja, a colonização. A colonialidade, por sua vez, é o rastro da subjugação da metrópole sobre a colônia, o pensamento hegemônico que se consolidou a partir de uma relação autoritária entre colonizadores e colonizados e que produz influência determinante sobre os países e os povos que foram colonizados. Para Assis (2014), é a distinção entre colonialidade e colonialismo que explica a continuidade da dominação colonial, mesmo após as independências dos países colonizados, ao reproduzir relações de poder, subalternidades e hierarquias raciais. Tais relações hierárquicas podem ser observadas nos mais diversos campos das organizações sociais como, por exemplo, nas concepções curriculares que orientam nossos processos educacionais.

Ao efetuar o apagamento do ponto de vista do conhecimento da cultura e da história de matriz africana, bem como dos povos originários, nas instituições escolares que são orientadas por uma cultura exclusivamente etnobranca, a educação nega às(aos) descendentes mais diretas(os) desses povos a possibilidade de reconhecimento de si mesmas(os) no ambiente escolar. Entretanto, se considerarmos que o patrimônio cultural constituído por esses povos está presente em todas(os) nós, como povo e nação, podemos afirmar que a omissão de suas contribuições em nossos currículos não é uma perda que atinja apenas a quem deles descende, mas também às(aos) consideradas(os) brancas e brancas - que também são brasileiras(os) e, como tais, constituídas(os) por essas heranças culturais. Nesse aspecto, também não é demasiado afirmar que a repetição sistemática desse modo de abordar o conhecimento contribui para a consolidação do racismo na sociedade brasileira. Muito embora estejamos convictas que o processo colonial e a forma como ele se reflete nas práticas curriculares até os dias de hoje tenha se mostrado tão danoso aos povos indígenas quanto aos povos africanos escravizados e seus descendentes, detemos nossa reflexão sobre a negritude, por tratar-se do nosso lugar político e social de fala.

O professor Tomaz Tadeu da Silva (2002, p. 129) traça uma relação entre currículo e constituições de subjetividades, que sublinhamos aqui, pois dialoga amplamente com essa discussão. $\mathrm{O}$ autor indaga:

Em que medida o currículo contemporâneo, apesar de todas as suas transformações e metamorfoses ainda está moldado pela herança epistemológica colonial? Em que medida as noções de nacionalidade e raça, forjadas no contexto da conquista e da expansão colonial, continuam predominantes nos mecanismos de formação de identidade e subjetividade embutidos no currículo oficial?

Tais questionamentos, levantados por Silva (2002), remetem a uma proposição curricular pós-colonial, vinculada às teorias do currículo pós-críticas, que discutem e lançam novas perspectivas para as construções curriculares de hoje. Para o autor, as teorizações tradicionais acerca do currículo intencionam uma abordagem pretensamente "neutra" do conhecimento. Nessa ideia de neutralidade - defendida por setores reacionários da sociedade - a visão convencional do currículo limita-se a lidar com temas como avaliação, metodologia, didática, planejamento, objetivos, aprendizagem, entre outros. Evidentemente, esses tópicos 
são caros à educação. Contudo, observamos que essas categorizações não podem ser alijadas dos problemas sociais que nos constituem como povo há séculos, tais como: o abismo social entre ricos e pobres, a falta de acesso às condições básicas de sobrevivência por parte de uma camada importante da população, além do racismo estrutural que perpassa todas as relações sociais.

Ainda conforme Silva, as concepções curriculares pós-críticas consideram temas como alteridade, identidade, diferença, subjetividade, saber-poder, gênero, raça, sexualidade e multiculturalismo como fundamentos para "um importante deslocamento na nossa maneira de conceber o currículo" (SILVA, 2002, p. 17). É possível concluir, em face da reflexão de Silva, que as teorias pós-críticas se aproximam do compromisso assumido pela Base Nacional Comum Curricular (BRASIL, 2018) com a educação integral, uma vez que esta

[r]econhece, assim, que a Educação Básica deve visar à formação e ao desenvolvimento humano global, o que implica compreender a complexidade e a não linearidade desse desenvolvimento, rompendo com visões reducionistas que privilegiam ou a dimensão intelectual (cognitiva) ou a dimensão afetiva. Significa, ainda, assumir uma visão plural, singular e integral da criança, do adolescente, do jovem e do adulto considerando-os como sujeitos de aprendizagem - e promover uma educação voltada ao seu acolhimento, reconhecimento e desenvolvimento pleno, nas suas singularidades e diversidades. (BRASIL, 2018, p. 14).

Para seguirmos esta linha de pensamento, que aborda a associação entre currículo, diversidade e discute a questão da neutralidade, convocamos a escrita da professora Nilma Lino Gomes (2013, p. 56), que fala, no trecho a seguir, especificamente sobre a educação pública. Para a autora,

[...] compreender a relação entre diversidade e currículo implica delimitar um princípio radical da educação pública e democrática: a escola pública se tornará cada vez mais pública na medida em que compreender o direito à diversidade e o respeito às diferenças como um dos eixos norteadores da sua ação e das práticas pedagógicas. Para tal, faz-se necessário o rompimento com a postura de neutralidade diante da diversidade que ainda se encontra nos currículos e em várias iniciativas de políticas educacionais, as quais tendem a se omitir, negar e silenciar diante da diversidade.

Até aqui, desenhamos um pouco esse cenário de formação social que conta com saberes, cultivos, experiências sociais, políticas e religiosas de diferentes matizes e origens, porém narrados e difundidos com base em um ponto de vista unívoco, que se apropriou dessa multiplicidade e dispôs dela desde os seus parâmetros. Consequentemente, nossos currículos escolares também se erigiram a partir desse círculo unidimensional de narrativa. Isso posto, gostaríamos de tecer, urdir a tais apontamentos, algumas indagações que possam nos lançar em outros fios dessa discussão e, quiçá, desentrelaçar em ideias mais propositivas em torno das experiências curriculares nas escolas: que modos de ser, estar e agir no mundo se inauguram a partir de um currículo que privilegia determinados saberes em detrimento de outros? De que forma essa concepção curricular interfere nas relações raciais que se estabelecem na escola? Como as crianças negras se produzem em relação às crianças não negras, ao considerarmos o espectro de subalternidade e a segregação que paira sobre elas? Como as crianças brancas se produzem em relação às crianças racializadas, ao levarmos em conta que as narrativas apresentadas em sala de aula as colocam em uma posição de pretensa superioridade sobre suas(seus) colegas não brancas e não brancos? Como produzir experiências curriculares que forjem outras narrativas e, consequentemente, outras relações raciais?

Não temos aqui a intenção de esgotar essas questões, nem mesmo de aprofundá-las para além desse prólogo, a partir do qual lançamos nossa perspectiva de análise. Diferente disso, nosso propósito será o de examinar essas questões fundamentadas na premissa da teoria dos Estudos da Performance. 


\section{"Do avesso do mesmo lugar"}

Entendemos que aliar os Estudos da Performance ao campo da Educação possibilita traçar uma estratégia que rompa com a proposição eurocentrada do currículo. Nossa adesão a tal campo, como ferramenta teórica na concepção de uma orientação curricular decolonial, deve-se ao lugar privilegiado que o corpo, a presença física e a corporeidade ocupam em sua elaboração. Com efeito, esses mesmos elementos, que são basilares para as especulações teóricas em torno da performance, são também a matéria vital desde a qual se constituem o Teatro e a Pedagogia Teatral, seara sobre a qual atuamos como professoras e artistas de teatro que somos.

Ademais, conforme já expusemos anteriormente, o corpo é também alvo por excelência dos processos de subalternização empreendidos pela desventura colonial. Dessa maneira, não é de surpreender que, no espaço escolar, o corpo seja colocado em segundo plano em comparação à aquisição dos conhecimentos formais, que são validados pela lógica racionalista de origem europeia. Acreditamos que, conforme o pensamento de Luciana Athayde Paz e Gilberto Icle (2020, p. 5), o "entretecimento entre educação e performance nos permitirá, talvez, desestabilizar determinadas naturalizações acerca das escolas e dos currículos. Essa desestabilização poderia ser pensada pelo viés de um denominador comum: o corpo”.

Não obstante, queremos evidenciar, desde já, que não tencionamos lançar aqui mais uma proposição unívoca, que simplesmente substitua as práticas curriculares sedimentadas no discurso colonial. Não ambicionamos trazer a potencialidade da performance como solução e/ou panaceia para a problemática que apontamos ao redor dos currículos escolares. Sabemos que há, certamente, nas diversas áreas de conhecimento, contribuições teóricas que se apresentam como possibilidades legítimas de elaboração de currículos orientados por princípios decoloniais. Nesse sentido, não nos deteremos em esmiuçar os conceitos de performance e/ou performatividade, mesmo porque, de acordo com o professor Marcelo Andrade Pereira (2012, p. 3), quando questionamos:

O que é Performance? A pergunta, embora pertinente, não encerra de fato um objeto preciso ou mesmo um conceito universalizável, refere apenas uma infinidade de objetos, de acepções e, por conseguinte, de outras tantas questões. Talvez o modo para melhor nos aproximarmos do objeto performance seja não por intermédio da pergunta que busca capturar especificamente o que ela é, mas de que é composta; isso implica indicar na investigação os sentidos que ela conforma, assim como os contextos a que ela pertence. Só alhures, então, pode-se apreender conceitualmente esse objeto - a performance -, visto configurar-se antropológico e não histórico; processual e não final; de delimitação problemática, de significação variável, possível.

Assim, ao invés de encalçar uma conceituação exata para a performance, que insiste em não se deixar aprisionar, desejamos tomar a ideia da performance como potência de outros modos de experiência curricular, quiçá outras maneiras de circunscrever saberes e conhecimentos. Atentaremos, então, para as relações tecidas por professoras(es), pesquisadoras(es) e estudiosas(os) que discutem, por meio de suas práticas artísticas, pedagógicas e intelectuais, a relação possível entre performance e educação.

Por exemplo, para Gilberto Icle e Mônica Torres Bonatto (2017, p. 10), a “interseção da performance com a educação nos possibilita pensar para além da demarcação de saberes e conhecimentos, exigindo uma forma de organização pautada pela experiência coletiva”. Ainda de acordo com Icle e Bonatto (2017, p. 25-26), desse modo, "a performance nos provoca a repensar tanto os currículos (não apenas escolares) quanto a manutenção da hierarquização de saberes”.

Ainda conforme afirma o professor Gilberto Icle (2010), relacionar a ideia da performance com a educação pode conduzir a experiências diferentes das convencionais e, assim, questionar as estruturas cristalizadas e o pensamento hegemônico. Para tanto, é preciso desvencilhar-se da ideia de performance vinculada ao acontecimento artístico e entendê-la como "ferramenta de análise da ação humana" (ICLE; BONATTO, 2017, p. 26), ou ainda "na sua manifestação como ação e prática social e na sua qualidade 
performativa, ou seja, na sua Performatividade" (ICLE, 2010, p. 12). Nas palavras de Icle e Bonatto (2017, p. 11), "a performance [...] para compreender e propor mudanças no âmbito da educação, significa, a um só tempo, a ritualização de comportamentos e a possibilidade inventiva de romper com essas repetições”. Gilberto Icle (2010, p. 15) indica ainda que

[...] os Estudos da Performance oferecem uma rica gama de possibilidades, na qual a performance e a performatividade aparecem como instrumentos pelos quais é possível pensar as relações sociais, as políticas públicas, as identidades de gênero e de raça, a estética, a infância, os rituais, a vida cotidiana, entre outros.

Ora, se pinçarmos, dessa relação de campos enumerados por Icle, especificamente, as relações de raça e entendermos o currículo como parte integrante das políticas públicas em Educação, podemos pensar nos Estudos da Performance como um possível detonador para uma proposição de currículo decolonial.

Conforme Luiz Fernandes Oliveira (2016), o termo decolonial - associado aos chamados intelectuais decoloniais -, remete à viabilidade de um pensamento crítico que parte dos subalternizados que, orientados por essa visão, podem empreender "a tentativa de construção de um projeto transdisciplinar, caracterizando-se também como força política para se contrapor às tendências acadêmicas dominantes de perspectiva de construção de conhecimento histórico e social" (OLIVEIRA, 2016, p. 35). Ao aplicar o termo decolonial às questões ligadas ao campo da performance, Simão e Sampaio (2018, p. 674) afirmam que o que se pode esperar da decolonialidade é "encontrar uma identidade que não aquela imposta pelos europeus, ainda que suas influências permaneçam".

A partir dessa proposta, é possível projetar um caminho na direção do que, nas palavras de Janet O'Shea (2018, p. 751), seria “um novo marco epistemológico que proporciona agenciamento e visibilidade àqueles que antes eram marginalizados e buscam uma nova geo-reconfiguração política de diferentes tipos de conhecimento". Como mulheres negras, artistas, professoras e pesquisadoras, esse caminho nos seduz e nos instiga na luta por uma educação antirracista. Esse paradigma educacional qualifica-se, justamente, por promover novas experiências pedagógicas capazes de enfrentar as práticas de exclusão, além de dirimir os mecanismos de silenciamento perpetrados nas nossas relações sociais e reiterados no ensino escolar.

\section{Considerações finais: pra tudo terminar em samba}

Para nós, propositoras desta problematização, ao menos duas questões nos assaltam a percepção e nos fazem pensar em algo mais assertivo na relação com os currículos. Foram essas questões que nos levaram a oferecer a presente análise para apreciação. Referimo-nos à potência da performance como espaço/tempo de ritualização dos comportamentos, associada a um projeto decolonial de currículo que inclua a diversidade de saberes que povoam o imaginário popular brasileiro e estabeleça, desde as vozes ainda inauditas, novas referências epistêmicas. Ou seja, trata-se de um conjunto de operações que mobilizam diretamente o modo como nos relacionamos com os diferentes sujeitos da educação, com especial atenção aos corpos subalternizados. Quiçá, tomar a potência da performance no seu marco corpóreo e relacional como mote para instituir outros modos de percepção e relação entre sujeitos/sujeitas que aduzam ao próprio reconhecimento do outra/outro como detentor(a) de saberes. Saberes reconhecíveis quando vistos, escutados, sentidos de múltiplas formas, nomeados, articulados, ritualizados.

Para finalizar, retornamos ao samba da Mangueira, nossa inspiração inicial, para apontar que um dos importantes caminhos para esse novo marco epistemológico, como nos inspira a performance - agora em sua acepção carnavalesca -, será também o de "ouvir as Marias, Mahins, Marielles, Malês" (HISTÓRIA..., 2019), o que significa, para retomar o princípio desta discussão, compreender o processo de silenciamento e apagamento de um importante legado cultural constituidor da nossa nação, especialmente nos currículos e experiências da educação formal. Nesse sentido, o processo de escuta dessas vozes pode se constituir em uma prática performática na qual a oitiva é tão vital quanto os modos de fazê-las ou deixá-las soar. Dito 
de outra forma, performar a escuta, desde a experiência advinda dela própria, é um processo complexo e delicado, no qual o que é feito de maneira intencional é tão importante quanto o que não estava previsto, mas se tornou possível precisamente em razão da sua força, a força da escuta.

\section{Referências}

ADICHIE, Chimamanda Ngozi. O perigo de uma história única. São Paulo: Companhia das Letras, 2019.

ASSIS, Wendell Fischer Teixeira. Do colonialismo à colonialidade: expropriação territorial na periferia do capitalismo. CADERNO CRH, Salvador, v. 27, n. 72, p. 613-627, set./dez. 2014.

BRASIL. Lei no 10.639, de 9 de janeiro de 2003. Altera a Lei no 9.394, de 20 de dezembro de 1996, que estabelece as diretrizes e bases da educação nacional, para incluir no currículo oficial da Rede de Ensino a obrigatoriedade da temática «História e Cultura Afro-Brasileira», e dá outras providências. Diário Oficial da União: seção 1, Brasília, DF, p. 1, 10 jan. 2003. Disponível em: http://www.planalto.gov.br/ccivil_03/leis/2003/l10.639.htm. Acesso em: 2 jul. 2020.

BRASIL. Lei $\mathrm{n}^{\circ}$ 11.645, de 10 março de 2008. Altera a Lei $\mathrm{n}^{\circ}$ 9.394, de 20 de dezembro de 1996, modificada pela Lei $n^{\circ} 10.639$, de 9 de janeiro de 2003, que estabelece as diretrizes e bases da educação nacional, para incluir no currículo oficial da rede de ensino a obrigatoriedade da temática "História e Cultura Afro-Brasileira e Indígena". Diário Oficial da União: seção 1, Brasília, DF, p. 1, 11 mar. 2008. Disponível em: http://www.planalto.gov.br/ccivil_03/_Ato20072010/2008/Lei/L11645.htm. Acesso em: 2 jul. 2020.

BRASIL. Ministério da Educação. Base Nacional Comum Curricular. Brasília: MEC/SEB, 2018. Disponível em: http://basenacionalcomum.mec.gov.br/images/BNCC_EI_EF_110518_versaofinal_site.pdf. Acesso em: 9 abr. 2019.

GOMES, Nilma Lino. Diversidade e currículo. In: TRINDADE, Azoilda Loretto da (org.). Africanidades Brasileiras e Educação. Rio de Janeiro: Acerp; Brasília: TV Escola, 2013. p. 55-57. Disponível em: https://cdnbi.tvescola.org.br/ contents/document/publicationsSeries/1426109893818.pdf. Acesso em: 11 maio 2020.

HISTÓRIA para ninar gente grande. Compositores: Danilo Firmino, Deivid Domênico, Mamá, Márcio Bola, Ronie Oliveira, Tomaz Miranda. Intérprete: Marquinho Art'Samba. Rio de Janeiro: Universal Music: Edimusa, 2019. $1 \mathrm{CD}$, faixa 5.

ICLE, Gilberto. Para apresentar a performance à educação. Educação e Realidade, Porto Alegre, v. 35, n. 2, p. 11-21, maio/ago. 2010.

ICLE, Gilberto; BONATTO, Mônica Torres. Por uma pedagogia performativa: a escola como entrelugar para professores-performers e estudantes-performers. Cadernos Cedes, Campinas, v. 37, n. 101, p. 7-28, jan./abr. 2017.

MALDONADO-TORRES, Nelson. A topologia do ser e a geopolítica do conhecimento: modernidade, império e colonialidade. Revista Crítica de Ciências Sociais, Coimbra, n. 80, p. 71-114, mar. 2008. Disponível em: https://www.kilombagem.net.br/ wp-content/uploads/2015/07/MALDONADO-TORRES-Topologia-do-Ser.pdf. Acesso em: 6 mar. 2017.

OLIVEIRA, Luiz Fernandes de. O que é uma educação decolonial? Revista Novamerica, Rio de Janeiro, n. 149, p. 35-39, jan./mar. 2016. Disponível em: http://www.novamerica.org.br/Revista_digital/0149/revista_free.php. Acesso em: 27 nov. 2018.

O'SHEA, Janet. Decolonizar o currículo? Possibilidades para decolonizar a formação em performance. Revista Brasileira de Estudos da Presença, Porto Alegre, v. 8, n. 4, p. 750-762, out./dez. 2018. Disponível em: https://seer.ufrgs.br/presenca/article/ view/87007. Acesso em: 9 mar. 2019.

PAZ, Luciana Athayde; ICLE, Gilberto. Currículo-documento, Currículos-performance. Educação em Revista, Belo Horizonte, v. 36, e222728, 2020. Disponível em https://www.scielo.br/pdf/edur/v36/1982-6621-edur-36-e222728.pdf. Acesso em: 11 set. 2020.

PEREIRA, Marcelo de Andrade. Performance e Educação: relações, significados e contexto de investigação. Educação em Revista, Belo Horizonte, v. 28, n. 1, p. 289-312, mar. 2012. Disponível em: https://www.scielo.br/scielo.php?script= sci_arttext\&pid=S0102. Acesso em: 11 ago. 2020.

SANTOS, Antônio Bispo dos. Colonização, Quilombos: modos e significações. Brasília: UNB, 2015.

SILVA, Tomaz Tadeu da. Documentos de Identidade: uma introdução às teorias do currículo. Belo Horizonte: Autêntica, 2002. 
SIMÃO, Marina Fazzio; SAMPAIO, Juliano Casimiro de Camargo. Corpo e descolonialidade em composição poética cênica. Revista Brasileira de Estudos da Presença, Porto Alegre, v. 8, n. 4, p. 665-690, out./dez. 2018. Disponível em: https://seer.ufrgs.br/presenca/article/view/78809. Acesso em: 22 mar. 2019.

Data de submissão: 15/08/2020

Data de aceite: 22/09/2020 